\title{
Enhancing Metacognitive Knowledge of Cognition among Junior Secondary Students with Mathematics Disability in Everyday Arithmetic
}

\author{
Nduka Wonu*, Orolobo Paul-Worika \\ Department of Mathematics/Statistics, Ignatius Ajuru University of Education, Port Harcourt, Nigeria \\ *Corresponding author: wonu.nduka@iaue.edu.ng
}

Received November 11, 2018; Revised January 19, 2019; Accepted February 15, 2019

\begin{abstract}
This study investigated the efficacy of metacognitive instructional strategy in the improvement of the knowledge of cognition among junior secondary students with Mathematics Disability (MD) in everyday arithmetic in Port Harcourt Local Government Area (LGA) of Rivers State, Nigeria. Pre-test, post-test quasi-experimental design was used. A total of 60 Junior Secondary Class 3 (JSC3) students with MD participated in the study. A diagnostic instrument, teacher judgment, and the internal examination results were used as criteria for the identification and selection of JSC3 students with MD for participation. Three instruments were used for data collection, viz: Everyday Arithmetic Problem-Solving Achievement Test (EAPSAT), Mathematics Disability Diagnostic Test (M2DT), and Metacognitive Strategy Assessment (MSA). The instruments were respectively used to measure everyday arithmetic achievement, diagnosis and metacognitive knowledge of cognition. The Cronbach alpha was used to determine the reliability of each section of MSA (declarative knowledge, $\alpha=0.81$, conditional knowledge, $\alpha=0.84$, procedural knowledge $\alpha=0.78$ ). The test-retest method was used to determine the reliability of EAPSAT and M2DT to obtain indices of 0.83 and 0.80 respectively. The research questions were answered using mean and standard deviation whereas the hypotheses were tested using Analysis of Covariance (ANCOVA). The findings among others established that the metacognitive knowledge of students improved over time; there were significant main effects of metacognitive strategy on student procedural, declarative and conditional knowledge respectively. A recommendation of the study is that teachers should adopt the metacognitive strategy while teaching everyday arithmetic.
\end{abstract}

Keywords: metacognition, strategy, everyday arithmetic, mathematics disability

Cite This Article: Nduka Wonu, and Orolobo Paul-Worika, "Enhancing Metacognitive Knowledge of Cognition among Junior Secondary Students with Mathematics Disability in Everyday Arithmetic." American Journal of Educational Research, vol. 7, no. 2 (2019): 153-160. doi: 10.12691/education-7-2-6.

\section{Introduction}

With the advancement of knowledge in all spheres of human endeavour and the growing competition among nations to occupy vantage positions in a new world influenced by science and technology, there is a renewed commitment by many countries including Nigeria, to the teaching and learning of mathematics, to cope with the emerging challenges of the $21^{\text {st }}$ century. To a large extent, mathematics is at the centre of solving human problems. This underscores the importance of mathematics to everyday human activities. It is also in recognition of this significance that mathematics is made a compulsory subject in primary and secondary schools in Nigeria so that pupils and students would get adequate background information and knowledge about the concept, content, and philosophy of mathematics. Mathematics teachers are also encouraged to develop skills that would make their teaching of the subject interesting and enjoyable to learners. Notwithstanding various steps taken by successive governments and education administrators in Nigeria to advance student mathematical attitude, achievement in mathematics in national examinations has not been impressive. Poor mathematical performance or Mathematics Disability (MD) is also experienced at the tertiary levels of education which in the researchers' view, is a consequence of the poor foundation of mathematics learning in the primary and secondary school levels. Numerous factors such as a sense of fear, dislike for Everyday Arithmetic concepts and symbols, lack of enthusiasm to understand the subject and application of wrong method of communication deplored by the teacher can also be linked with MD.

Mathematics Disability (MD) is a form of learning disability that hampers the capacity of an otherwise intelligent child from learning mathematics. It is a number processing and calculation disorder, which is conceived as a brain-based disorder of probable genetic origin, inherited from one's parents [1]. Students with Mathematics Disability usually have difficulty in remembering or recalling figures, 
writing numbers or numerals and applying mathematical procedures correctly and generally perform poorly in mathematical exercises and problems-solving. Mathematics disability is identified when the student's achievement level or ability in mathematics fall below his expected age, school or intelligence level. Mathematics disability can be assessed using a range of diagnostic or measurement instruments. Such task should include top knowledge of mathematical facts and procedures, basic numbers processing skills, ability to identify a small and big number of objects at a glance and as well as the ability to use different number notational formats.

Mathematics teachers could be good solvers of problems in mathematics but some of them may not know how or do not adequately use an appropriate strategy to engage their students in problem-solving. This brings to the fore, an issue that requires a critical and scientific investigation, to know that a fundamental challenge on the poor performance of mathematics is likely to be associated with the inadequacy of the curriculum to address the method or strategy of learning mathematics as the traditional instructional model appears out-of-date and inadequate to meet the demands of the new age resulting in the high level of dismal performance and under-achievement in mathematics by secondary school students. It is, therefore, necessary to adopt a new strategy, the metacognitive strategy, which will actively involve the learner in a way that he is able to analyze and solve mathematical problems by monitoring and controlling his mental processes.

The metacognitive strategy, developed by J.H. Flavell is the knowledge, awareness or consciousness by a person on the efficacy of his own cognitive or mental processes and controlling those processes in order to achieve the goal of problem-solving [2]. The strategy refers to the knowledge and experiences learners have about their cognitive process; and how to plan and monitor a task to achieve progress by thinking and controlling the learning process including appraising the method, raising critical questions and observations, correcting errors and generally analyzing the learning strategy including the learner's self-re-examination and his attitude or behaviour to what he is learning. Metacognition was dichotomized [3] into two broad categories: (i) knowledge of cognition, as activities that involve conscious reflection on one's cognitive abilities and activities; and (ii) regulation of cognition, as activities as regards self-regulatory mechanisms during problem-solving task performance. Brown indicated that these two aspects of metacognition are strongly related, each depending on the other, however, can be distinguished.

Metacognitive knowledge, also known as knowledge of cognition could be seen as what persons know regarding their own cognition or about cognition generally. It was further established [3] that knowledge of cognition is statable, stable, fallible and age-dependent (develop with age). The study further emphasized that knowledge of cognition has three key dimensions, namely declarative knowledge, (knowing "about" things), procedural knowledge (knowing "how" to do things) and conditional knowledge (knowing the "why" and "when" aspects of cognition). In corroboration with Brown's assertions, [4] indicated the three kinds of metacognitive awareness that makeup knowledge of cognition are declarative, conditional and procedural knowledge.

Several theorists established that metacognitive knowledge appears early and continually develop at least all through adolescence [3,5]. Studies have established that adults tend to possess extra knowledge about their personal cognition and are better able to describe that knowledge than do young children [6,7]. Young learners routinely demonstrate and apply knowledge about cognition but lack the ability to express that knowledge [8]. Surprisingly, even adults have great difficulty describing their own expert cognition clearly [9]. Therefore, the extent to which students with MD use declarative, conditional and procedural knowledge when solving mathematical problems in the secondary schools in Rivers State becomes questionable.

The Declarative knowledge involves a learner's knowledge about himself and about the factors that affect his performance. Adults possess more knowledge about the cognitive processes associated with memory. Likewise, good learners seem to possess more knowledge about their own memory and are apter than poor learners to apply their knowledge [10]. Declarative knowledge is related to the regulation of cognition. Knowledge about the execution of procedural skills could be referred to as procedural knowledge [11].

Learners with a high level of Procedural knowledge apply skills more automatically. They are smarter to order strategies efficiently and utilize qualitatively diverse strategies to solve problems [12]. In addition, it has been found that assisting younger learners advance in their procedural knowledge enhances their on-line problemsolving performance [13]. A comparison of groups of students in which learners solved problems with or without a problem-solving prompt card has been explored [14]. The finding of the study indicated that students who received explicit procedural training on the use of the prompt card solved more problems on a test than the control group.

Conditional knowledge involves knowing when and why to apply different cognitive actions [15]. It is the relative application of cognitive procedures. Older children have been found to possess more conditional knowledge about their own learning than kindergarten children. In addition, adults and older children are better able than younger learners to selectively apportion their attention based on conditional task demands $[7,16]$. Studies have found positive relationships between conditional knowledge and regulation of cognition [11,17]

The metacognitive strategy has been tested and proven to be efficacious to students with learning disability regardless of whether or not they have dyscalculia [18,20]. It is, therefore, appropriate to adopt this strategy which is already widespread in several parts of the world. Also, some research works on metacognitive strategy on students mathematical learning achievement in the secondary schools in Rivers State have been carried out. The effectiveness of a constructivist class of instructional models in advancing the senior secondary student geometry achievement in Abua/Odual Local Government Area of Rivers State, Nigeria has been investigated [19]. The metacognitive instructional model and teaching for understanding were the constructivist instructional model 
adopted by the experimental groups in the study. The findings established among others that there was a significant difference in the learning achievement between senior secondary students taught using metacognitive instructional model and those taught geometry using problem-based learning model in favour of metacognition. The efficacy of metacognitive strategy on the achievement of students with Development Dyscalculia (DD) in Number and Numeration was also explored [20]. The regulation of cognition was a response variable in the study. According to the findings, JSC3 students with DD lack good prediction ability, as well as monitoring and evaluation skills, and are usually unable to reflect on a possible solution to mathematical problems while metacognitive strategy improved the capacity of such students to learn mathematics better and improve their problem-solving ability more effectively. Metacognition is therefore, an area of difficulty for children with a mathematical disability because such students lack adequate knowledge concerning their own metacognitive process and products and are therefore unable to understand the problem they have [21]. As a result of this, they find it difficult to plan an appropriate strategy to use to solve any problem or monitor the procedures they use and often fail to recognize when they have made an error [22].

Students with a mathematical disability must be taught metacognitive skill in order to understand and know how to plan, predict, monitor and evaluate the steps and procedures being used to achieve a result. Academically successful students acquire the self-understanding that supports effective strategies to solve problems while students with MD do not adequately possess this knowledge [20]. A key challenge to teachers is to identify this disparity as those with mathematical disability strive to deal with their predicament or continue to falter and fail. Thus, even for teachers, understanding how metacognition develops is key to understanding how children become successful problem solvers in mathematics [22].

The present study is an intervention study to better teaching and learning of mathematics by determining the level of knowledge of cognition in Everyday Arithmetic by students with MD in junior secondary schools in Port Harcourt, in a bid to address the dismal performance of students in mathematics. It will add to the store of vital information on the need to review the traditional model of instruction and apply the metacognitive strategy by getting the students to be more actively involved in the learning process not merely by listening attentively to the teacher, but by stimulating their mental processes to think and also to monitor and to control their thinking of everyday arithmetical concepts.

\subsection{Problem Specification}

Poor performance in mathematics by students in secondary schools has remained a major challenge to teachers and students, as it has created a great concern to parents, administrators, and policymakers. The conventional or traditional method of teaching appears to be obsolete or inappropriate as the method does not stimulate the mental process of the student to engage in critical mathematical thinking in which a student feels challenged to solve unfamiliar mathematical problems, "so students have great difficulties comprehending and assimilating mathematics concepts taught them in the class [23].

Mathematics Disability (MD) is a key factor to student mathematical underperformance. Dyscalculia is a mathematics disability. It has been observed that dyscalculia is a major setback to learning mathematics among children and students with dyscalculia could have difficulty in identifying and selecting appropriate strategies, organizing information, monitoring problem-solving processes as well as evaluating problems for accuracy. It has also been established [24], that many school teachers in Port Harcourt were ineffective in teaching mathematics because of the conventional approach they apply.

This study is a peek into the improvement of the metacognitive knowledge through instructions using metacognitive strategy. This will consequently advance the student problem-solving skills. This study therefore seeks to answer the question: What is effect of the metacognitive instructional strategy on the knowledge of cognition among junior secondary school students with mathematics disability in Everyday Arithmetic?

\subsection{Purpose of the Study}

The purpose of this study is to determine the effect of metacognitive instructional strategy on the knowledge of cognition among JSC3 students with MD in everyday Arithmetic in Rivers State. In particular, the study would:

1. Determine the conditional knowledge of students with MD taught everyday arithmetic using metacognitive strategy and those taught with problem-solving strategy.

2. Determine the procedural knowledge of students with MD taught everyday arithmetic using metacognitive strategy and those taught with problem-solving strategy.

3. Determine the declarative knowledge of students with MD taught everyday arithmetic using metacognitive strategy and those taught with problem-solving strategy.

\subsection{Research Questions}

This study was guided by the following research questions:

1. What mean difference exists in the conditional knowledge of students with MD taught everyday arithmetic using metacognitive strategy and those taught problem-solving strategy?

2. How did students with MD taught everyday arithmetic using metacognitive strategy differ over mean procedural knowledge compared to those taught using problem-solving strategy?

3. What is the mean difference in the mean declarative knowledge between students with MD taught everyday arithmetic using metacognitive strategy and those taught using problem-solving strategy?

\subsection{Research Hypotheses}

The following null hypotheses were tested at .05 level of significance 
$\mathbf{H}_{\mathbf{0 1}}$ : There is no significant effect of metacognitive strategy on the mean conditional knowledge of students with MD in everyday arithmetic.

$\mathbf{H}_{\mathbf{0 2}}$ : There is no significant effect of metacognitive strategy on the mean procedural knowledge of students with MD in everyday arithmetic.

$\mathbf{H}_{\mathbf{0 3}}$ : There is no significant effect of metacognitive strategy on the mean declarative knowledge of students with MD in everyday arithmetic.

\section{Methods and Materials}

\subsection{Research Design}

The pretest-posttest quasi-experimental design was used. The purpose was to observe the relative effectiveness of the independent variable (i.e. teaching strategy) on student knowledge of cognition in everyday arithmetic. Classes were randomly assigned as treatment and control groups. The dependent variable was metacognitive knowledge as measured by Metacognitive Strategy Assessment (MSA). The independent variable of the study was the teaching strategy. This design was used because it is impossible to completely randomize the subjects in the school as this may result in disorganization of the classes.

\subsection{Participants}

A total of 60 JSC3 students took part in the study. The JSC3 class was particularly chosen because it is considered introductory to higher levels of Mathematics teaching and learning. Purposive sampling technique was adopted to select Port-Harcourt Local Government Area in River State. Then simple random sampling technique was used to select two co-educational public junior secondary schools from the area. In the selected schools, one was used as the experimental group while the other was used as the control group.

\subsubsection{Diagnosis, Identification and Selection}

1. For a child to be considered as having MD, that child had to perform significantly poorly in mathematics than would be expected based on the general school results [25]. To establish this, the mean score of two mathematics test scores (scores of first and second term results) of all the JSC3 students in each selected school was computed. Students with mean scores less than the overall mean were considered MD students.

2. Secondly, a diagnostic instrument, Mathematics Disability Diagnostics Test (M2DT) was administered to the students identified as having MD from the school result. Again, students with scores less than the median score were categorized as having severe MD while those whose scores were greater than the median score of all the students with MD were considered as having mild MD. The severity of MD was not considered in this study. A similar approach was adopted [20] in phase two of the identification of students with developmental dyscalculia in number and numeration.

3. Finally, teachers' judgments were also used since research [26] has shown that teacher judgments were valuable assessments of students' achievement-related behaviours. A total of 60 students with MD were used, comprising of thirty (30) students with MD in the treatment and control groups respectively.

\subsection{Instruments for Data Collection}

Three instruments were concurrently used in data collection for this study. They include:

1. Mathematics Disability Diagnostics Test(M2DT)

2. Everyday Arithmetic Problem-Solving Achievement Test (EAPSAT)

3. Metacognitive Strategy Assessment (MSA)

At the design stage of the instruments, the time available for the test, type of test items to be used and other factors like age, ability level of the students and type of process objectives to be measured were considered.

\subsubsection{M2DT}

Mathematics Disability Diagnostics Test (M2DT) was exclusively used to diagnose and identify the students with MD for participation in the study. The M2DT was a 25-item instrument designed by the researcher. It was designed based on five content areas in everyday arithmetic for JSC3 students. The same Table of specification (Table 1) was used to compose multiple choice questions equivalent or parallel to items of EAPSAT. The items of this M2DT evaluated the lower and higher cognitive processes with a few difficult and easy questions and obtained difficulty and discrimination indices.

\subsubsection{EAPSAT}

Everyday Arithmetic Problem-Solving Achievement Test (EAPSAT) was used to quantify the academic achievement of the students with MD in everyday arithmetic. The EAPSAT is a 25-item instrument with multiple choice options to be marked over 100 . The EAPSAT was based on five content areas in everyday arithmetic for JSC3 students. The total number of items for each topic, process objectives based on the relative importance and the time spent in teaching the topics guided the decision on the design of EAPSAT using the test blueprint (Table 1). During the preparation of EAPSAT, the focus was on knowledge, comprehension, and application of the content areas.

Table 1. Test blue print for EAPSAT/M2DT

\begin{tabular}{|c|c|c|c|c|}
\hline \multirow[b]{2}{*}{ Content topics } & \multicolumn{4}{|c|}{ Process objectives } \\
\hline & 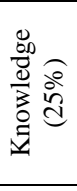 & 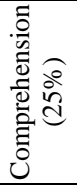 & 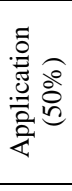 & 胥 \\
\hline Fraction (20\%) & 1 & 1 & 3 & 5 \\
\hline Ration (20\%) & 1 & 1 & 3 & 5 \\
\hline Proportion (20\%) & 1 & 1 & 3 & 5 \\
\hline Percentage (20\%) & 1 & 1 & 3 & 5 \\
\hline Simple/compound interest (20\%) & 1 & 1 & 3 & 5 \\
\hline Total (100\%) & 5 & 5 & 15 & 25 \\
\hline
\end{tabular}




\subsubsection{MSA}

Metacognitive Strategies Assessment (MSA) was used to assess the metacognitive knowledge of cognition of the students with MD. The students rated their declarative, conditional and procedural knowledge in a problem-solving situation in everyday arithmetic. MSA was retrieved and adapted from [11].

\subsection{Scoring of the Instruments}

Similar scoring methods were used for M2DT and EAPSAT. Furthermore, the MSA in this study assessed metacognitive knowledge. The scoring processes explained below were adopted in both pre-test and post-test stages of the assessment.

\subsubsection{Assessment of Metacognitive Knowledge}

a. Conditional knowledge: To rate the conditional knowledge, each student was requested to indicate in writing why he/she gave the rating for the difficulty. Absolutely correct reason for difficulty attracts 4 marks while somewhat correct reason attracts 2 marks and a wrong reason attracts zero $(0)$ mark.

b. Procedural knowledge: To quantify the procedural knowledge of the students, each student was requested to indicate (enumerate) the procedure (steps) adopted while solving each of the tasks in EAPSAT.

c. Declarative knowledge: The students were asked to declare the level of difficulty they had in each of the questions on EAPSAT on a scale of 1-9. The lesser number indicates a higher level of difficulties while higher numbers indicate a lower difficulty level.

How difficult is this problem to you? for example, what is the sum of $1 / 2$ and $1 / 4$ ?

Easy 987654321 Difficult.

\subsubsection{Assessment of Cognitive Achievement using EAPSAT}

To evaluate the cognitive achievement of the students, each student was asked to solve the 25 questions (problems) in EAPSAT and select (circle) the correct options from a multiple-choice option (A, B, C, \& D). Selection of the correct option attracted 4 marks, while the selection of the wrong option attracted a score of zero (0). The maximum score attainable by a student was 100 and the minimum score was zero (0). For the purpose of this study, the data obtained using EAPSAT were not presented. The EAPSAT was used to facilitate the assessment of the student metacognitive knowledge of cognition in using MSA.

\subsection{Validity and Reliability of the Instruments}

The instruments were validated by experts in mathematics education. The instruments were modified to measure student achievement in Everyday Arithmetic and Metacognitive knowledge of cognition. The reliability of the instruments, EAPSAT and M2DT, were determined using test-retest method whereas the internal consistency of MSA was determined using Cronbach Alpha respectively. The reliability indices of 0.83 and 0.80 were obtained for
EAPSAT and M2DT respectively. The reliability for each section of the MSA were obtained (declarative knowledge, $r_{a}=0.81$, conditional knowledge, $r_{a}=0.84$ and procedural knowledge, $r_{a}=0.78$ ).

\subsection{Data Collection}

The EAPSAT and MSA were administered to each group as a pre-test and the scripts were collected before the commencement of the lesson by the teacher. The experimental group was taught Everyday arithmetic using Metacognitive instructional strategy whereas the control group was taught the same topic using problem-solving strategy. The regular mathematics teachers in the sampled school carried out the experiment in the treatment and control groups. The teaching lasted for 5 weeks. The teacher in the experimental group was given intensive training on the theoretical and practical aspect of the metacognition.

\subsubsection{Treatment Group}

Before the experiment commenced, students in the two groups attempted questions as pre-test on EAPSAT. They were asked to declare their perceived level of difficulty of each of the questions on EAPSAT using MSA simultaneously. They were also required to indicate the reasons (conditions) why they gave such rating of the difficulty of each item. After the retrieval of the pretest scripts, the students were grouped into five (5) groups comprising of six (6) members. They were asked to choose their group names, slogans (cheers) and group leader using a smart wired card. This was done to enable the group members to have a deeper knowledge of the attributes and abilities of one another. Next, to the completion of pre-test and groupings, the metacognitive strategy instruction using problem solving activities was implemented to develop the metacognitive knowledge of cognition of students in the treatment group. The teaching was aimed at developing student metacognitive knowledge practically during problem solving activities. The researchers planned the activities carried out in the treatment group. The students were given details on the activities involved in the application of metacognitive training instruction based on their level. In addition, the students were given metacognitive problem-solving worksheet during these classes. They were asked to work according to the steps outlined in the worksheets while solving the problems. Other materials such as cardboard papers, rule, calculators, etc were provided for the students to enable them have concrete materials to make their problem solving activities more realistic. They were also asked to take up individual projects/problems to be presented in a large group discussion on an appointed date.

The role of the teacher during these activities was to guide the students and supervise the operation of the activities, asking questions that enhanced the smooth running of the process and lead the students to critical thinking. While the students were busy with the problems in work-sheets during problem-solving activities, the teacher monitored them and asks questions when necessary in order to trigger the metacognitive thinking of the students. The normal 40 minutes duration (after school hours) was observed per lesson supervised by the 
researchers. At the end of 5 weeks, EAPSAT and MSA were re-administered to the students as post-test. The scripts were collected, marked and scored over 100 for both pretest and post-test. The data obtained were tabulated and coded for data analysis.

\subsubsection{Control Group}

The students in the control group were made to solve the same problems used in the experimental group. The teacher generally presented the problems to the students, gave time for a solution and then guide them through the problem and asked the students to control their solutions, guided by the process of problems-solving. The entire process followed during the pre-test and post-test using EAPSAT and MSA were also observed in the control group.

\subsection{Data Analysis}

The research questions were answered using mean and standard deviation while the hypotheses were tested using Analysis of Covariance (ANCOVA) at .05 level of significance.

\section{Results}

Table 2. Mean and standard deviation of student Conditional Knowledge (CDK) scores on MSA

\begin{tabular}{lcccccc}
\hline & \multicolumn{4}{c}{ Pre- CDK } & \multicolumn{2}{c}{ Post- CDK } \\
Group & $\mathrm{N}$ & Mean & SD & Mean & SD & Mean gain \\
\hline Experimental & 30 & 2.60 & 0.82 & 52.47 & 26.46 & 49.87 \\
Control & 30 & 0.40 & 0.20 & 14.67 & 21.00 & 14.27 \\
MDBG & & 2.20 & & 37.80 & & \\
\hline
\end{tabular}

$\mathrm{MDBG}=$ Mean difference between the groups.

Table 2 shows the mean and standard deviation of student conditional knowledge scores on MSA. It further shows that pre-test mean scores of the students in the experimental group on conditional knowledge was $2.60 \pm$ 0.82 while that of their control group counterparts was $0.40 \pm 0.20$. The difference in the mean pre-test scores between the groups was 2.20. The post-test mean score on conditional knowledge of the students in the experimental group was $52.47 \pm 26.46$, while that of their control group counterparts was $14.67 \pm 21.00$. The post-test mean difference between the groups was 37.80. The mean gain score in the experimental group was 49.87 whereas that of the control group counterparts was 14.27.

Table 3. Mean and standard deviation of student Procedural Knowledge (PRK) scores on MSA

\begin{tabular}{|c|c|c|c|c|c|c|}
\hline \multirow[b]{2}{*}{ Group } & \multirow[b]{2}{*}{$\mathrm{N}$} & \multicolumn{2}{|c|}{ Pre- PRK } & \multicolumn{2}{|l|}{ Post- PRK } & \multirow[b]{2}{*}{ Mean gain } \\
\hline & & Mean & $\mathrm{SD}$ & Mean & SD & \\
\hline Experimental & 30 & 0.53 & 1.38 & 39.27 & 20.63 & 38.74 \\
\hline Control & 30 & 0.13 & 0.51 & 12.53 & 20.39 & 12.40 \\
\hline MDBG & & 0.40 & & 26.74 & & \\
\hline
\end{tabular}

MDBG= Mean difference between the groups

Table 3 shows the mean and standard deviation of student procedural knowledge scores on MSA. It further shows that the mean pre-test scores of the students in the experimental group on procedural knowledge was $0.53 \pm$ 1.38 while that of their control group counterparts was $0.13 \pm 0.51$. The difference in the mean pre-test scores between the groups was 0.40 . The post-test mean score on procedural knowledge of the students in the experimental group was $39.27 \pm 20.63$, while that of their control group counterparts was $12.53 \pm 20.39$. The post-test mean difference between the groups was 26.74. The mean gain score in the experimental group was 38.74 whereas that of the control group counterparts was 12.40 .

Table 4. Mean and standard deviation of student Declarative Knowledge (DCK) scores on MSA

\begin{tabular}{lcccccc}
\hline & \multicolumn{4}{c}{ Pre- DCK } & \multicolumn{2}{c}{ Post- DCK } \\
Group & $\mathrm{N}$ & Mean & SD & Mean & SD & Mean gain \\
\hline Experimental & 30 & 14.40 & 23.11 & 72.53 & 7.57 & 58.13 \\
Control & 30 & 1.67 & 5.49 & 20.00 & 23.74 & 18.33 \\
$M D B G$ & & 12.73 & & 52.53 & & \\
\hline
\end{tabular}

MDBG= Mean difference between the groups.

Table 4 shows the mean and standard deviation of student declarative knowledge scores on MSA. It further shows that pre-test mean scores of the students in the experimental group on declarative knowledge was $14.40 \pm$ 23.11 while that of their control group counterparts was $1.67 \pm 5.49$. The difference in the mean pre-test scores between the groups was 12.73 . The post-test mean score on procedural knowledge of the students in the experimental group was $72.53 \pm 7.57$, while that of their control group counterparts was $20.00 \pm 23.74$. The difference in the mean post-test scores between the groups was 52.53. The mean gain score in the experimental group was 58.13 whereas that of the control group counterparts was 18.33 .

Table 5. Summary of Analysis of Covariance (ANCOVA) of student Conditional Knowledge (CDK)

\begin{tabular}{lcccccc}
\hline Source & SS & df & MS & F & Sig. & $\eta^{2}$ \\
\hline Pre-CDK & 701.277 & 1 & 701.277 & 1.234 & .271 & .021 \\
Treatment & 16886.187 & 1 & 16886.187 & 29.719 & .000 & .343 \\
Error & 32386.856 & 57 & 568.190 & & & \\
Total & 122124.000 & 60 & & & & \\
Corrected Total & 54520.733 & 59 & & & & \\
\hline
\end{tabular}

a. $\mathrm{R}$ Squared $=.406$ (Adjusted $\mathrm{R}$ Squared $=.385$ ), $\eta^{2}=$ Partial Eta Squared, $\mathrm{SS}=$ Sum of Squares, MS= Mean Square.

Table 5 shows the summary of ANCOVA of student Conditional Knowledge (CDK). It established that there was a significant effect of metacognitive strategy on the mean conditional knowledge of students with MD in everyday arithmetic $\left(\mathrm{F} 1,57=29.719, \mathrm{p}=.000, \eta^{2}=.343\right)$. The null hypothesis one was rejected at .05 alpha level.

Table 6. Summary of ANCOVA of student Procedural Knowledge (PRK)

\begin{tabular}{lcccccc}
\hline Source & SS & df & MS & F & Sig. & $\eta^{2}$ \\
\hline Pre-PRK & 270.193 & 1 & 270.193 & .638 & .428 & .011 \\
Treatment & 10976.484 & 1 & 10976.484 & 25.925 & .000 & .313 \\
Error & 24133.140 & 57 & 423.388 & & & \\
Total & 75372.000 & 60 & & & & \\
Corrected Total & 35123.400 & 59 & & & & \\
\hline
\end{tabular}


a. R Squared $=.313$ (Adjusted R Squared $=.289$ ).

Table 6 shows the summary of ANCOVA of student Procedural Knowledge (PRK). It proved that there was a significant effect of metacognitive strategy on the mean procedural knowledge of students with MD in everyday arithmetic (F1, 57=25.925, $\mathrm{p}=.000, \eta^{2}=.313$ ). The null hypothesis two was rejected at .05 alpha level.

Table 7. Summary of Analysis of Covariance (ANCOVA) of student Declarative Knowledge (DCK)

\begin{tabular}{lllllll}
\hline Source & SS & df & MS & F & Sig. & $\eta^{2}$ \\
\hline Pre-DCK & 1276.058 & 1 & 1276.058 & 4.347 & .042 & .071 \\
Treatment & 31326.188 & 1 & 31326.188 & 106.721 & .000 & .652 \\
Error & 16731.409 & 57 & 293.533 & & & \\
Total & 187840.000 & 60 & & & & \\
Corrected Total & 59403.733 & 59 & & & & \\
\hline
\end{tabular}

a. R Squared $=.718$ (Adjusted R Squared $=.708$ ).

Table 7 shows the summary of ANCOVA of student Declarative Knowledge (DCK). It indicated that there was a significant effect of metacognitive strategy on the mean declarative knowledge of students with MD in everyday arithmetic (F1, 57=106.721, p=.000, $\left.\eta^{2}=.652\right)$. The null hypothesis three was rejected at .05 alpha level.

\section{Discussion of Findings}

The results of this study are discussed below based on the response variables over which data was collected, analyzed and presented above. These include components of metacognitive knowledge of cognition, viz: conditional knowledge, procedural knowledge, and declarative knowledge.

\subsection{Conditional Knowledge}

The result proved that the conditional knowledge of the students with MD in both groups improved with time (Table 2). The post-test conditional knowledge of the students was higher than the pretest in both groups. It was found that the mean conditional knowledge of the students with MD in the experimental group was higher than that of those in the control group. However, the pre-test conditional knowledge scores of both groups were low. This was consistent with the finding of [21] who established that metacognition is an area of difficulty for children with a mathematical disability because such students lack adequate knowledge concerning their own metacognitive process and products and are therefore unable to understand the problem they have. There was a significant main effect of metacognitive strategy on student conditional knowledge in everyday arithmetic (Table 5). Consistent with the present findings, [20] found that metacognitive strategy improved the capacity of students to learn mathematics better and improve their problem-solving ability more effectively.

\subsection{Procedural Knowledge}

The result showed that the procedural knowledge of the students with MD in both groups improved over time
(Table 3). The post-test procedural knowledge was higher than the pre-test procedural ability in both groups. The mean gain in procedural knowledge was higher in the experimental group. There was a significant main effect of metacognitive strategy on student procedural knowledge in everyday arithmetic (Table 6). The present finding is consistent with the findings of [18] who established that metacognitive strategy has been tested and proven to be efficacious to students with learning disability regardless of whether or not they have dyscalculia. This is consistent with the study of [12] which maintains that metacognitive skills can be improved through the use of qualitative strategies to solve problems.

\subsection{Declarative Knowledge}

The result established that the declarative knowledge of the students was found to improve with time (Table 4). The student mean post-test declarative knowledge scores were higher than their mean pre-test scores in both groups. Learners appear to have more knowledge about their own memory and use what they know when properly guided. Also [27] noted that individuals store pieces of information on the various matter in their mind and when confronted with a problem, they access and use the necessary data to answer the question posed. This supports the position that metacognitive skills can be improved through instruction. It was found that the mean declarative knowledge of students with MD taught everyday arithmetic using metacognitive strategy was higher than those taught using the problem-solving strategy. There was a significant main effect of metacognitive strategy on the declarative knowledge of students with MD in Everyday Arithmetic (Table 7). This finding is in corroboration with an earlier study [20], which established that students with mathematical deficiency lack metacognitive regulation skills, but metacognitive strategy improves the capacity of such students to learn mathematics better and improve their problem-solving skills more effectively.

\section{Conclusion}

The purpose of the study was to determine the efficacy of metacognitive strategy on the metacognitive knowledge of cognition (procedural, conditional and declarative knowledge) among students with MD in Everyday Arithmetic. Specifically, they improved in knowing about everyday arithmetic, how to solve the problem involved and they also enhanced their knowledge of why and when to take any action while solving problems. Students of both groups actually had difficulties with the metacognitive knowledge as evident in their very low mean scores in the prospective assessment of the three aspects of metacognitive knowledge measured. This is remarkable as it corroborates an earlier study [21] which proved that metacognition is an area of difficulty for learners with a mathematical disability because such students lack adequate knowledge concerning their own metacognitive process and products and are therefore unable to understand the problem they have. However, this study has proven that there is ability in every disability. Students with a mathematical disability also have mathematical 
strengths. The metacognitive strategy enhanced, improved and facilitated student understanding of the concept of Everyday Arithmetic. The metacognitive knowledge of the students with MD improved over time. In particular, the students have a better understanding of their weaknesses and strengths in problem-solving. Furthermore, students in the experimental group taught with metacognitive strategy improved in their conditional, procedural and declarative knowledge more than those in the control group taught with the traditional problem-solving method. Hence, it is believed that if an effective instructional model like the metacognitive strategy is adopted in the mathematics classroom, student problem-solving skills in everyday arithmetic will improve whether they have MD or not.

\section{Recommendations}

Based on the findings of the study, the following recommendations are made.

1. To mitigate the impact of MD in learning everyday arithmetic, effective teaching strategy such as metacognitive strategy should be used in addition to other instructional methods.

2. Mathematics teachers at Junior Secondary School level should diagnose their class to identify students with MD and find means of remediation to avoid the effect of possible boomerang at higher levels of mathematics study.

3. Since students with severe and mild MD are found in almost all mathematics classrooms, mathematics teachers should apply metacognitive strategies as well as other effective activity-oriented strategies to mitigate the negative effect of this problem.

\section{References}

[1] Butterworth B: The development of Arithmetical abilities, Journal of Child Psychology and Psychiatry 46(1), 3-18 (2005)

[2] Flavell, J. H: Metacognitive aspects of problem solving. In L. Resnick (Ed.), The nature of intelligence. Hillsdale, NJ: Lawrence Erlbaum (1976).

[3] Brown, A: Metacognition, Executive Control, Self-Regulation and Other More Mysterious Mechanisms. In: Weinert, F.E. \& Kluwe, R.H., Eds., Metacognition, Motivation and Understanding, Hillsdale, 65-116. (1987).

[4] Baker, L., Cerro, L.C: Assessing metacognition in children and adults. In: Schraw G, Impara J, editors. Issues in the measurement of metacognition. Lincoln, NE: Buros; 99-145. (2000).

[5] Garner, R., \& Alexander, P. A: Metacognition: Answered and unanswered questions. Educational Psychologist. 24: 143-158. (1989).

[6] Baker, L: Metacognitive, Comprehension Monitoring and the Adult Reader, Educational Psychology Review, 1(1), 3-38 (1989).

[7] Reynolds, RE: Selective attention and prose learning: Theoretical and empirical research. Educational Psychology Review. 4(4): 345-391. (1992).

[8] Montague, M: The effects of cognitive and metacognitive strategy instruction on the mathematical problem solving of middle school students with learning disabilities. Journal of Learning Disabilities, 25, 230-248. (1992).

[9] Bereiter, C., and Scardamalia, M: Surpassing Ourselves: An Inquiry into the Nature and Implications of Expertise. Chicago, IL: Open Court (1993).

[10] Garner, R: Metacognition and reading comprehension. Norwood, NJ: Ablex (1987).

[11] Desoete, A., Roeyers, H., \& Buysse, A: Metacognition and mathematical problem solving in grade 3. Journal of Learning Disabilities, 34, 435-449. (2001).

[12] Stanovich, K.E: Concepts in developmental theories of reading skill: Cognitive resources, automaticity, and modularity. Dev Rev 10:72-100 (1990).

[13] Pressley, M., Borkowski, J. G., and Schneider, W: Cognitive strategies: Good strategy users coordinate Metacognition and knowledge. In Vasta, R., and Whitehurst, G. (eds.), Annals of Child Development (Vol. 4), JAI Press, Greenwich, CT. 89-129 (1987).

[14] King, A: Effects of training in strategic questioning on children's problem-solving performance. Journal of Educational Psychology. 83, 305-317 (1991).

[15] Lorch, R. F., Lorch, E. P., and Klusewitz, M. A: College students' conditional knowledge about reading. Journal of Educational Psychology. 85: 239-252. (1993).

[16] Miller, P. H: Metacognition and Attention, In Forrest-Pressley, D. L., McKinnon, E. G., \& Waller T. G. (Eds.), Metacognition, Cognition, and Human Performance, Academic Press, New York, pp. 181-221. (1985).

[17] Justice, E. M., \& Weaver-McDougall, R. G:. Adults' knowledge about memory: Awareness and use of memory strategies across tasks. Journal of Educational Psychology, 81(2), 214-219. (1989).

[18] Van der Walt, M., \& Maree, K: Do mathematics facilitators implement metacognitive strategies? South African Journal of Education, 27(2), 223-241(2007).

[19] Wonu, N \& Harrison, I.S: Constructivist class of instructional models and senior secondary student geometry achievement. International Journal of Multidisciplinary Research and Development. 5(12). 98-103. (2018).

[20] Wonu, N: Effects of Metacognitive Strategy on the Achievement of Students with Developmental Dyscalculia in Number and Numeration. Unpublished M.Ed Dissertation, University of Port Harcourt (2012).

[21] Boudah, D. J. \& Weiss, M. P: Learning Disabilities Overview, Eric Digest (2002).

[22] Lucangeli, D., Cornoldi, C., \& Tellarini, M: Mathematics and metacognition: What is the nature of the relationship? Mathematical Cognition, 3, 121-139. (1997).

[23] Ali, M.H: Improving Teaching in Our schools, Science Teachers Association of Nigerian (STAN), 1, 26-28. (2008).

[24] Ogunkunle R. A: Teachers Effectiveness as Emergent Issues Confronting Quality Mathematics Education in Primary Schools in Rivers State, African Journal of Historical Sciences in Education, 5(12), 73-80. (2009).

[25] American Psychiatric Association: Diagnostic and Statistical Manual of Mental Disorders, (4 ${ }^{\text {th }}$ Edition, text revision) Washington, DC (2000).

[26] Winne, P.H., \& Perry, N.E: Measuring self-regulated learning. In M. Boekaerts, P.E. Pintrich \& M. Zeidner (Eds.), Handbook of Self-regulation. San Diego: Academic Press. 531-566. (2000).

[27] Rysz,T: Metacognition in Learning Elementary Probability and Statistics. A PhD Thesis, University of Cincinnati. (2004). 